\title{
Prevalence of Neonatal Meningitis With Special Emphasis on Csf Changes in Cases of Neonatal Septicemia: A Cross Sectional Study

\author{
Dr. Abhay Charan $\mathrm{Pal}^{1}$, Dr. Pooja Sinha ${ }^{2}$, Dr. Snehanshu Chakraborti ${ }^{3}$, Dr. \\ Ritwik Mukherjee ${ }^{4}$, Dr. Sudipta Bandyopadhyay ${ }^{5}$. \\ ${ }^{2}$ Post-Graduate Trainee; Department Of Pediatric Medicine, B.S. Medical College, Bankura, West Bengal; \\ India. \\ ${ }^{4}$ Post-Graduate Trainee; Department Of Pediatric Medicine, B.S. Medical College, Bankura, West Bengal; \\ India. \\ ${ }^{5}$ Post-Graduate Trainee; Department Of Pediatric Medicine, B.S. Medical College, Bankura, West Bengal; \\ India.
} \\ ${ }^{1}$ Associate Professor; Department Of Pediatric Medicine, B.S. Medical College, Bankura, West Bengal; India. \\ ${ }^{3}$ Professor And Head; Department Of Pediatric Medicine, B.S. Medical College, Bankura, West Bengal; India.
}

\begin{abstract}
Neonatal Septicemia is one of the most commonly made diagnoses is most centres. Meningitis is associated in some cases of neonatal septicemia. Sign-symptoms of both septicemia and meningitis are closely simulating making CSF examination mandatory in almost every cases. This institution-based cross-sectional observational study was conducted in SNCU \& NICU of B S Medical College, Bankura, West Bengal, India. Among total 100 neonatal septicemia cases recruited, meningitis was diagnosed in 23 cases; $43 \%$ of which did not demonstrate any sign-symptoms of CNS infection emphasizing the need to perform CSF examination in neonatal septicemia-patients.
\end{abstract}

Keywords: Neonatal Septicemia; Neonatal meningitis; Cross-sectional Study; Observational Study; CSF Changes; India.

\section{Introduction}

Neonatal Sepsis or Sepsis neonatorum is a clinical syndrome characterised by signs and symptoms of infection with or without accompanying systemic bacterial infection (bacteremia) occuring in the first month of life. It encompasses neonatal septicemia, meningitis, pneumonia, arthritis, osteomyelitis and urinary tract infections ${ }^{1,2,3}$. Neonatal meningitis is infection of the meninges and CNS in the first month of life and is diagnosed if CSF culture is positive or CSF microscopy and biochemistry are suggestive of meningitis in the setting of septicemia ${ }^{4}$.

Sepsis is one of the commonest cause of neonatal mortality contributing to about 1.6 million deaths worldwide $e^{4,5}$. Incidence of neonatal sepsis in India according to data from National Neonatal Perinatal Database (NNPD, 2002-03) is 30 per 1000 livebirths ${ }^{4}$.

Features of neonatal sepsis are largely nonspecific and comprise of hypothermia or fever (former is more common in preterm low birth weight infants), lethargy, poor cry, refusal to suck, abdominal distension, poor perfusion, pallor, abnormal skin color, prolonged capillary refill time, hypotonia, brady-or tachycardia, respiratory distress, apnea, jaundice, hypo/hyperglycemia. Late features include sclerema, shock, disseminated intravascular coagulation (DIC), pulmonary hemorrhage and collapse ${ }^{6}$.

Neonatal meningitis is caused by the same pathogen causing neonatal sepsis and incidence of meningitis is around one tenth to one fourth of that of neonatal sepsis.

Early clinical features of neonatal meningitis are clinically indistinguishable from those of sepsis ${ }^{8}$. Classical signs suggestive of CNS infection like irritability or depressed sensorium, seizures, apnea, full of bulging fontanelle are either less commonly observed or, are late signs of meningitis emphasizing the importance of high index of suspicion and a lumber puncture in evaluation of neonatal sepsis ${ }^{9}$.

Importance of LP as a part of diagnostic evaluation of suspected neonatal sepsis has been the subject of much controversies and debate.

Interpretation of $\mathrm{CSF}$ (cerebrospinal fluid) is a difficult process and there is considerable overlap between reports from normal neonates and neonates with meningitis.

Four parameters are trditionally evaluated in CSF study apart from culture and gram stain. They are total WBC count, percentage neutrophil count, glucose and protein.

However there is absence of well-established cut-off values of these parameters. Inspite of above mentioned limitations CSF examination is an integral part of evaluation of neonatal sepsis because of lack of reliable clinical and laboratory markers to predict which neonate with septicemia will have meningitis and also 
because of the fact that neonatal meningitis is a more ominous entity requiring higher antibiotics for longer duration $^{8,10}$

This study thus intends to emphasize the need to perform CSF examination in certain designated cases of neonatal septicemia and thereby attempting to recommend the routine use of lumber puncture as a part of workup of neonatal septicemia.

\section{Aims and Objectives}

This study aims to provide a clinico-epidemiological profile of evaluated neonatal sepsis cases with special emphasis on neonatal meningitis. Therefore the objectives of this study are:

1. To study cases of neonatal sepsis with special reference to the associated CSF changes in order to estimate the prevalence of neonatal meningitis in this setting.

2. To study the distribution of lumber puncture positive neonatal sepsis cases amongst the presenting EONS and LONS cases.

\section{Materials And Methods}

This prospective study was carried out in SNCU \& NICU wards of Department of Pediatric Medicine; B.S. Medical College, Bankura, West Bengal. The study period extended from February 2014 to January 2015 (1 year). One hundred neonates were included after fulfilling of inclusion criteria and written consent from parents/guardians.

Inclusion criteria comprised of important clinical features viz. Poor feeding, tempture instability, not doing well, abdominal distension, vomiting, apnea, tachyphea, grunting, oliguria, hypotension, brady/tachycardia, irrtability/lethargy, seizures, full fontanel, jaundice, bleeding, sclerema, DIC, collapse ${ }^{2}$.

Clinically suspected cases underwent 'blood-culture' study and were classified into

a) Culture positive neonatal sepsis

b) Culture negative(clinical) neonatal sepsis

If blood-cultures were found sterile after 48 hours, in a neonate having clinical features of sepsis the presence of any one of the following criteria was taken as enough for assigning probable diagnosis of infection ${ }^{4}$

a) Existence of predisposing(risk) factors viz. LBW/prematurity, maternal fever within two weeks of delivery, foul smelling liquor, rupture of membrane $>24$ hours, single unclean/> 3 sterile vaginal examination during labor, prolonged labor, perinatal asphyxia.

b) Positive sepsis screen comprising of raised CRP(C-reactive protein), abnormal ANC(absolute neutrophil count), abnormal $1 / \mathrm{T}$ ratio [immature to total neutrophil ratio], raised micro-ESR. Sepsis screen is positive if $\geq 2$ parameters are positive ${ }^{11,12}$.

c) Radiological evidence of pneumonia.

Contraindications to perform CSF examination by Lumber puncture included raised intracranial pressure, bleeding neonate, infection of overlying skin, lumbosacral anomaly, very sick neonate.

After a detailed history was taken sepsis screen and blood cultures were sent to the pathilogy and microbiology department of this institute and then CSF study was performed in all septicemic neonates (apart from those having contraindications). CSF study was performed by pathology and biochemistry department.

Meningitis was labelled in a neonate with sepsis in :

a) Preterm neonates - If CSF WBC count $\geq 10 / \mathrm{cmm}$ or, glucose $<24$ or protein $>170 \mathrm{mg} / \mathrm{dl}$.

b) Term neonates - If CSF WBC count $>8$ or, glucose $<20$ or, protein $>120 \mathrm{mg} / \mathrm{dl}$.

Other investigations like Computerised Tomography(CT) or, Magnetic resonance imaging(MRI) of brain was done as and when required.

Data analysis was done using SPSS 20 for windows. Standard statistical tests were applied. Rates and proportions were calculated with $95 \%$ confidence intervals and level of significance was set at $\mathrm{P}<0.05$.

Ethical approval of the study and the consent to publish the clinical data derived from the study have been obtained from the Institutional Ethics Committee of B. S. Medical College; Bankura; West Bengal; India.

\section{Result and Analysis}

Out of total hundred $(n=100)$ neonates recruited in the study 65 were boys and 35 were girls. Fifty eight neoborns were inborn and 42 were outborns. Mean birth weight of the sample studied was 2280.80 gm. with a standard deviation of $579.75 \mathrm{gm}$. Twenty three (23) neonates demonstrated CSF changes suggestive of meningitis and seventy seven (77) cases did not. Mean gestational age of the study group was 36.71 wks with a standard deviation of $2.06 \mathrm{wk}$. Forty (40) neonates were preterm and sixty (60) were full term.

Table 1 shows frequency of neonatal meningitis among early onset neonatal sepsis (EONS) and late onset neonatal sepsis (LONS) 
Table 1: EONS / LONS

\begin{tabular}{|c|c|c|c|c|}
\hline & \multirow{3}{*}{$\begin{array}{c}\text { Neonatal Sepsis }(\mathrm{n}= \\
100)\end{array}$} & \multicolumn{3}{|c|}{ Neonatal Meningitis $(n=23)$} \\
\hline & & \multicolumn{3}{|c|}{$P$ value $=0.002$} \\
\hline & & No. & $\%$ (of Meningitis cases) & $\%$ \\
\hline EONS & 58 & 7 & 30 & $12(\%$ of EONS $)$ \\
\hline LONS & 42 & 16 & 70 & $38(\%$ of LONS $)$ \\
\hline
\end{tabular}

The neonatal sepsis cases studied were classified according to day of life with symptom onset into EONS (within first 72 hours of life) and LONS (after Day 3 of life). The prevalence of neonatal meningitis was significantly more amongst the LONS cases as shown in Table 1.

Table 2 shows blood-parameters in the study population subclassified into EONS/LONS groups.

Table 2: Blood Investigations In Eons Vs Lons

\begin{tabular}{|c|c|c|c|c|c|c|c|c|c|c|c|c|}
\hline \multirow[t]{2}{*}{$n=100$} & \multicolumn{2}{|c|}{ Low ANC } & \multicolumn{2}{|c|}{$\begin{array}{c}\text { ITR } \\
\text { Significant }\end{array}$} & \multicolumn{2}{|c|}{ Toxic granules } & \multicolumn{2}{|c|}{ CRP } & \multicolumn{2}{|c|}{$\begin{array}{l}\text { Micro-ESR } \\
\text { Significant }\end{array}$} & \multicolumn{2}{|c|}{$\begin{array}{c}\text { Low platelet } \\
\text { count }\end{array}$} \\
\hline & No & Yes & No & Yes & Absent & $\begin{array}{c}\text { Presen } \\
\mathbf{t}\end{array}$ & Negative & $\begin{array}{c}\text { Positi } \\
\text { ve }\end{array}$ & No & $\begin{array}{c}\text { Ye } \\
\text { s }\end{array}$ & Present & $\begin{array}{l}\text { Abs } \\
\text { ent }\end{array}$ \\
\hline EONS & 38 & 20 & 41 & 17 & 48 & 10 & 25 & 33 & 35 & 23 & 21 & 37 \\
\hline LONS & 29 & 13 & 29 & 13 & 26 & 16 & 20 & 22 & 24 & 18 & 10 & 32 \\
\hline P value & \multicolumn{2}{|c|}{.711} & \multicolumn{2}{|c|}{.860} & \multicolumn{2}{|c|}{.019} & \multicolumn{2}{|c|}{.654} & \multicolumn{2}{|c|}{.748} & \multicolumn{2}{|c|}{.186} \\
\hline
\end{tabular}

Table 2 shows the distribution of the EONS and LONS cases studied into various pertinent categories with only the sub-classification amongst preterm and term neonates and the presence or absence of toxic granules being statistically significant.

Table 3: Presenting symptoms of the neonates

\begin{tabular}{|c|c|c|c|c|c|c|}
\hline & Poor feeding & Lethargy & Fever & $\begin{array}{c}\text { Miscellaneous } \\
\text { symptoms }\end{array}$ & $\begin{array}{c}\text { Seizures } \\
\text { during } \\
\text { course of } \\
\text { illness }\end{array}$ & $\begin{array}{c}\text { Features } \\
\text { suggestive of CNS } \\
\text { involvement }\end{array}$ \\
\hline $\begin{array}{c}\text { Neonatal Sepsis } \\
(\mathbf{n = 1 0 0 )}\end{array}$ & 63 & 26 & 18 & 19 & 13 & 20 \\
\hline $\begin{array}{c}\text { Neonatal Meningitis } \\
(\mathrm{n}=23)\end{array}$ & $12(52 \%)$ & $\mathbf{6 ( 2 6 \% )}$ & $\begin{array}{c}5 \\
(22 \%)\end{array}$ & $\mathbf{7 ( 3 0 \% )}$ & $\mathbf{1 1 ( 4 8 \% )}$ & $13(57 \%)$ \\
\hline
\end{tabular}

Table 3 demonstrates the clinical presentation of neonatal sepsis with and without associated meningitis and show that they are clinically indistinguishable except for the relative preponderance of clinical features suggesting CNS involvement (seizures, shrill cry/bulging AF/abnormal neurological findings) during the course of the illness in meningitis.

Cry, reflex and activity were found to be significantly more depressed in neonatal meningitis patients associated with sepsis than those with neonatal sepsis alone.

Table 4: Shows the blood culture reports in the study population

\begin{tabular}{|l|c|}
\hline \multicolumn{1}{|c|}{ Neonatal sepsis $(\mathbf{n}=100)$} & Frequency \\
\hline No growth & 71 \\
\hline Klebsiella pneumoniae & 24 \\
\hline Staphylococcus aureus & 4 \\
\hline Escherichia coli & 1 \\
\hline
\end{tabular}

The study did not reveal any significant association between sepsis screen positively and growth on blood culture.

Table 5: shows CSF profile in the study group and also illustrates the corresponding value in cases of neonatal meningitis

\begin{tabular}{|l|c|c|c|c|c|c|}
\hline & \multicolumn{2}{|c|}{ CSF-Cell count $\left(/ \mathbf{m m}^{3}\right)$} & \multicolumn{2}{c|}{ CSF-Sugar $(\mathbf{m g} /$ dl) } & \multicolumn{2}{c|}{ CSF-Protein (mg/dl) } \\
\cline { 2 - 7 } & $\begin{array}{c}\text { Neonatal } \\
\text { sepsis }\end{array}$ & $\begin{array}{c}\text { Neonatal } \\
\text { meningitis }\end{array}$ & $\begin{array}{c}\text { Neonatal } \\
\text { sepsis }\end{array}$ & $\begin{array}{c}\text { Neonatal } \\
\text { meningitis }\end{array}$ & $\begin{array}{c}\text { Neonatal } \\
\text { sepsis }\end{array}$ & $\begin{array}{c}\text { Neonatal } \\
\text { meningitis }\end{array}$ \\
\hline Mean & $\mathbf{3 6}$ & $\mathbf{1 4 3 . 0 9}$ & $\mathbf{5 1}$ & $\mathbf{1 9 . 6 5}$ & $\mathbf{9 8}$ & 144.35 \\
\hline Median & 4 & 70 & 55 & 18 & 88 & 156 \\
\hline $\begin{array}{l}\text { Standard } \\
\text { deviation }\end{array}$ & 112 & 201.09 & 23 & 8.97 & 32 & 32.46 \\
\hline Minimum & $\mathbf{0}$ & $\mathbf{2 6}$ & $\mathbf{8}$ & $\mathbf{8}$ & $\mathbf{4 0}$ & $\mathbf{8 6}$ \\
\hline Maximum & $\mathbf{7 5 0}$ & $\mathbf{7 5 0}$ & $\mathbf{1 0 8}$ & $\mathbf{3 8}$ & $\mathbf{1 8 8}$ & $\mathbf{1 8 8}$ \\
\hline
\end{tabular}


Table 5 shows the range of CSF parameters found on evaluation of these neonatal sepsis cases and also the corresponding values in the neonates with associated meningitis.

Pre-discharge USG of brain revealed cerebral oedema in 16 neonates; intraventricular hemorrhage (IVH) in 1 neonate; not available in 7 neonates and 76 neonates did not reveal any abnormality.

Table 6: Illustrates the outcome of the neonates in this study

\begin{tabular}{|l|c|c|c|}
\hline \multicolumn{2}{|c|}{} & Neonatal sepsis (n=100) & Neonatal meningitis (n=23) \\
\hline \multirow{4}{*}{ USG Brain } & NAD & 76 & 4 \\
\cline { 2 - 4 } & Abnormal & 17 & 13 \\
\cline { 2 - 4 } & N. A. & 7 & 6 \\
\hline \multirow{2}{*}{$\begin{array}{l}\text { Neurological examination at } \\
\text { Discharge }\end{array}$} & Normal & 84 & 8 \\
\cline { 2 - 4 } & Abnormal & 9 & 6 \\
\cline { 2 - 4 } & N. A. & 7 & 17 \\
\hline Discharged & 93 & 6 \\
\hline Expired & 7 & \\
\hline
\end{tabular}

\section{Discussion}

The prevalence of neonatal meningitis among neonatal Sepsis cases was found to be $23 \%$ in this study. Some studies have shown that $20-30 \%$ of all cases of neonatal septicemia (Early or late) were associated with neonatal meningitis ${ }^{11}$. Our study conforms to those findings. National Neonatal Perinatal Database (NNPD) 2002-2003 has shown that $10.62 \%$ cases of sepsis in cases of intramural live births and $19.60 \%$ cases of sepsis in cases of extramural admissions had co-existing meningitis. Boys have been found to have outnumbered girls in almost all studies including NNPD report and our study-results are consistent with those observations ${ }^{4}$. In the present study $39 \%$ cases of neonatal meningitis were preterm and the rest were term babies. However other studies report that incidence of early onset neonatal bacterial meningitis is higher in preterm than term babies and incidence of late onset meningitis increases with decreasing gestational age $\mathrm{e}^{12,13,14}$.

In this study there is relatively higher prevalence of meningitis amongst LONS compared to EONS cases, this finding being consistent with previous studies ${ }^{15,16}$.

In our study $60 \%$ of neonates did not have typical symptoms suggestive of CNS infection, which is in conformity with previous observations ${ }^{17}$. In this series $35 \%$ of study population had an average neurological status i.e. cry, reflex, activity and $82 \%$ and $92 \%$ had a normal tone and posture respectively. Hypothermia was found to be more common in LBW neonates with sepsis which is consistent with other studies ${ }^{2,18}$. In this study 'sepsis screen' was found to be positive in 51\% cases included (diagnosed as clinical sepsis) and in 'sepsis' cases with CSF changes suggestive of associated meningitis. So it can be concluded that there no ideal test/combination of tests which can rule out confidently associated meningitis emphasizing the need of a CSF examination in 'neonatal sepsis' cases. This finding is corroborated by other reports also ${ }^{19,20}$.

In the present study, $29 \%$ of neonatal Sepsis has positive blood culture which closely agrees with most available datas ${ }^{21}$.

In our study 8 out of 23 neonates with CSF changes had a growth in blood culture; rest 15 was found to have a sterile blood culture. This finding strengthens the recommendation of performing CSF examination in all 'septicemic' neonates because in this series 15 cases would have been missed a diagnosis of CNS infection if CSF examination would not have been done.

Appropriate cut-off values for preterm and term neonates were used for assigning a diagnosis of meningitis using CSF cell count and protein level ${ }^{8}$. A low glucose level in CSF is the variable with greatest specificity for diagnosing meningitis ${ }^{22,23}$. studies ${ }^{4}$.

Our study revealed abnormal neuroimaging finding in $17 \%$ of cases which is in conformity with other

Mortality was found to be higher in cases of 'septicemia' with meningitis than in those without meningitis (i.e. 'septicemia' alone). Thus neonatal meningitis was associated with more adverse outcome than 'sepsis' alone.

\section{Conclusion}

1. It was found that many cases of neonatal sepsis had associated meningitis, a significant proportion revealed neither specific clinical signs-symptoms nor, positive blood culture/investigation pointing to CNS involvement. So this study emphasizes the necessity to perform CSF examination in all 'neonatal sepsis' cases.

2. Mortality and morbidity is found to be much higher in sepsis with associated meningitis than in cases with sepsis alone. 


\section{Contributions}

DR Sinha actually conducted the study. She collected, compiled and analysed all the data and also performed the statistical analysis.

DR Pal planned and supervised the study. He also drafted the final manuscript.

DR Chakraborti provided all sorts of guidance and help during the study and added important intellectual contents.

DR Mukherjee helped in conducting the study at all steps by all means.

DR Bandyopadhyay also provided necessary help and assistance during the entire study period.

The investigators are thankful to Mr. Md. Zahir for neatly designing and final typing of the manuscript.

The authors are really thankful to all personnel's of SNCU and NICU. But for their help this work would not have been possible.

Funding - None

Competing Interest - None

\section{References}

[1]. Morven s. Edwards. Postnatal Bacterial Infections. In: Fanaroff and Mertin's Neonatal -Perinatal Medicine, $10^{\text {th }}$ edn, Eds. Richard J. Martin, Avory A.Fanaroff, Michele C. Walsh, 2014, pp 791-804

[2]. Barbara J. Stoll and Andi L. Shane. Infection of the Neonatal Infant. In: Nelson Textbook of Pediatrics, $20^{\text {th }}$ edn, Eds. Kliegman, Stanton, St Geme, Schor, 2015, pp 909-925

[3]. Neonatal sepsis. In: AIIMS Protocols in Neonatology, $1^{\text {st }}$ edn, Eds Ramesh Agarwal, Ashok Deorari, Vinod K. Paul, 2015 pp $163-$ 173

[4]. NNPD, Report of the National Neonatal Perinatal Database (National Neonatalogy Forum) 2002-2003

[5]. Sankar MJ, Agarwal R, Deorari AK, Paul VK. Sepsis in the newborn. Indian J Pediatr. 2008; 75:261 -6

[6]. Gerdes JS, Polin R. Early diagnosis and treatment of neonatal sepsis. Indian J Pediatr 1998;65:63-78

[7]. Patricia Ferrieri and Linda D. Wallen. Neonatal bacterial sepsis. In: Avery's Diseases of the Newborn, $9^{\text {th }}$ edn, Eds Christine A. Gleason, Sandra E. Jull, 2012, pp 538-550

[8]. Sourabh Dutta, Sandeep Kadam, Shiv Sajan Saini, ON Bhakoo, NB Mathur. Management of Neonatal Sepsis. In: Evidence Based Clinical Practice Guidelines, by National Neonatology Forum, India, Eds ON Bhakoo, Praveen Kumar, Naveen Jain, Rhishikesh Thakre, Srinivas Murki, S Venkataseshan, 2010, pp 155-172

[9]. Kestenbaum LA, Ebberson J, Zorc JJ, Hodinka RL, Shah SS. Defining cerebrospinal fluid white blood cell count reference values in neonates and young infants. Pediatrics. 2010;125(2):257-264

[10]. Klein JO, Feigin RD, McCracken Jr GH. Report of the task force on diagnosis and management of meningitis. Pediatrics 1986; 78 : 959-982

[11]. Philip AG, Hewitt JR. Early diagnosis of neonatal sepsis. Pediatrics 1980; 65: 1036-41

[12]. Gerdes JS, Polin RA. Sepsis screen in neonates with evaluation of plasma fibronectin. Paediatr Infect Dis J 1987; 6: 443-6

[13]. Wiswell TE, Baumgart S, Gannon CM, Spitzer AR. No lumbar puncture in the evaluation for early neonatal sepsis: will meningitis be missed? Pediatrics 1995; 95: 803-6

[14]. Johnson CE, Whitwell JK, Pethe K et al. Term newborns who are at risk for sepsis: are lumbar puncture necessary? Pediatrics 1997; 99: E 10

[15]. Kumar P, Sarkar S, Narang A. Role of routine lumbar puncture in neonatal infection. J Paediatr Child Health 1995; 31: 8-10

[16]. Fielkow S, Reuter S, Gotoff SP. Cerebrospinal fluid examination in symptom-free infants with risk factors for infection. J Pediatr 1991; 119: 971-3

[17]. Chang Chien HY, Chiu NC, Li WC, Huang FY. Characteristic of neonatal bacterial meningitis in a teaching hospital in Taiwan from 1984-1997. J Microbiol Immunol Infect. 2000; 33: 100-104

[18]. Shalini Tripathi, G. K. Malik.Neonatal Sepsis: past, present and future. Internet Journal of Medical Update 2010 July; 5(2): 45-54

[19]. Schelonka RL, Yoder BA, desJardins SE, Hall RB, Butler J. Peripheral leukocyte count and leukocyte indexs in healthy newborn term infants. J Pediatr 1994; 125: 603-6

[20]. Fowlie PW, Schmidt B. Diagnostic tests for bacterial infection from birth to 90 days-a systematic review. Arch Dis Child Fetal Neonatal Ed 1998; 78: F92-F98

[21]. Mahale R, Dutta S, Ahluwalia J and Narang A. Baseline illness severity does not alter accuracy of neonatal sepsis screen. 2005. Postgraduate Institute of Medical Education and Research, Chandigarh, 2005

[22]. Smith PB, Garges HP, Cotton CM, Walsh TJ, Clark RH, Benjamin DK Jr. Meningitis in preterm neonates: importance of cerebrospinal fluid parameters. Am J Perinatol. 2008; 25(7): 421-426

[23]. Garges HP, Moody MA, Cotton CM, et al. Neonatal Meningitis: what is the correlation among cerebrospinal fluid cultures, blood cultures and cerebrospinal fluid parameters? Pediatrics. 2006; 117(4): 1094-1100 